\title{
Locating the Binding Domains in a Highly Selective Mixed Matrix Membrane via Synchrotron IR Microspectroscopy
}

DOI:

10.1039/C7CC08932E

\section{Document Version}

Accepted author manuscript

Link to publication record in Manchester Research Explorer

\section{Citation for published version (APA):}

Jacques, N. M., Rought, P. R. E., Fritsch, D., Savage, M., Godfrey, H. G. W., Li, L., Mitra, T., Frogley, M. D., Cinque, G., Yang, S., \& Schroder, M. (2018). Locating the Binding Domains in a Highly Selective Mixed Matrix Membrane via Synchrotron IR Microspectroscopy. Chemical Communications.

https://doi.org/10.1039/C7CC08932E

\section{Published in:}

Chemical Communications

\section{Citing this paper}

Please note that where the full-text provided on Manchester Research Explorer is the Author Accepted Manuscript or Proof version this may differ from the final Published version. If citing, it is advised that you check and use the publisher's definitive version.

\section{General rights}

Copyright and moral rights for the publications made accessible in the Research Explorer are retained by the authors and/or other copyright owners and it is a condition of accessing publications that users recognise and abide by the legal requirements associated with these rights.

\section{Takedown policy}

If you believe that this document breaches copyright please refer to the University of Manchester's Takedown Procedures [http://man.ac.uk/04Y6Bo] or contact uml.scholarlycommunications@manchester.ac.uk providing relevant details, so we can investigate your claim.

\section{OPEN ACCESS}




\section{Chemical Communications}

\section{COMMUNICATION}

\section{Locating the Binding Domains in a Highly Selective Mixed Matrix Membrane via Synchrotron IR Microspectroscopy}

Received 00th January 20xx, Accepted 00th January 20xx

DOI: $10.1039 / \times 0 \times x 00000 x$
Nicholas M. Jacques, ${ }^{\text {a }}$ Peter R. E. Rought, ${ }^{a}$ Detlev Fritsch, ${ }^{b}$ Mathew Savage, ${ }^{a}$ Harry G. W. Godfrey, Lei Li, ${ }^{a}$ Tamoghna Mitra, ${ }^{c}$ Mark D. Frogley, ${ }^{d}$ Gianfelice Cinque, ${ }^{d}$ Sihai Yang ${ }^{a *}$ and Martin Schröder ${ }^{a *}$

www.rsc.org/

The binding domains within a mixed matrix membrane (MMM) that is selective for $\mathrm{CO}_{2}$ comprising MFM-300(Al) and the polymer 6FDA-Durene-DABA have been established via in situ synchrotron IR microspectroscopy. The MOF crystals are fully accessible and play a critical role in the binding of $\mathrm{CO}_{2}$, creating a selective pathway to promote permeation of $\mathrm{CO}_{2}$ within and through the MMM. This study reveals directly the molecular mechanism for the overall enhanced performance of this $\mathrm{MMM}$ in terms of permeability, solubility and selectivity for $\mathrm{CO}_{2}$.

The area of metal-organic frameworks (MOFs) has expanded rapidly over the past two decades. These porous materials, constructed from metal nodes and organic linkers, show promise in a variety of applications including gas storage ${ }^{1,2}$ and separation, $^{3-5}$ catalysis, $^{6}$ proton conductivity ${ }^{7,8}$ and sensing ${ }^{9}$ owing to their unique guest binding and selectivity. To exploit MOFs more fully, interest has grown in the production of films and membranes. ${ }^{10}$ Pure MOF membranes and MOF films grown on a porous substrate (e.g., MOF-5 and ZIF-69) often adopt rigid and brittle structures with low processability. ${ }^{11,12}$ Also, there are often inherent limitations for MOF films grown on substrates since the substrate must be stable under the conditions used for making the MOF; therefore, often the MOF has to be grown under mild conditions. ${ }^{13-15}$

Mixed matrix membranes (MMMs) comprised of porous filler (e.g., MOFs, zeolites, silica) and a polymer binder are composite materials that may overcome these barriers. Indeed, MMMs can show improved stability and reproducibility over pure MOF membranes. ${ }^{8}$ Furthermore, fabrication of MMMs can effectively reduce the overall production costs since less MOF material is required compared with a pure MOF membrane. Several stable MOF-based

a. School of Chemistry, University of Manchester, Oxford Road, Manchester, M13 9PL,UK.Sihai.Yang@manchester.ac.uk; M.Schroder@manchester.ac.uk.

b. Fraunhofer IAP, FB3, Geiselbergstrasse 69, Potsdam-Golm, 14476, Germany. c. Department of Chemistry, University of Liverpool, Liverpool, L69 7ZD, UK.

d.Diamond Light Source, Harwell Science and Innovation Campus, Didcot, Oxfordshire, OX11 ODE, UK.

Electronic Supplementary Information (ESI) available: experimental details, SEM and EDX images and unprocessed infra-red spectra. See DOI: 10.1039/x0xx00000x

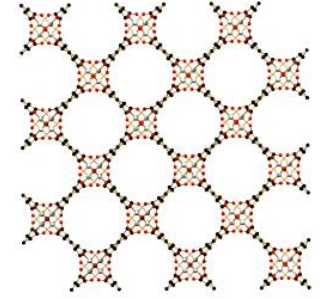

(a)

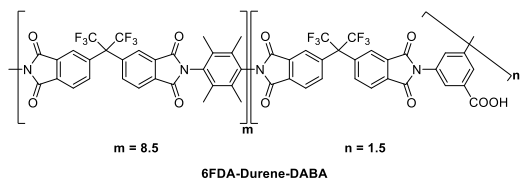

(b)
Figure 1. Views of (a) the crystal structure of MFM-300(Al) along the $c$-axis, and (b) the chemical structure of 6FDA-Durene-DABA (8.5/1.5)

MMMs have been fabricated using ZIF-8, ${ }^{16-17}$ UiO-66, ${ }^{18}$ MIL$53^{19-21}$ and MIL-101 $(\mathrm{Cr})^{22}$ which show good adhesion between the MOF and polymer components. MMMs can exhibit better gas separation performance than both the pure polymer and the MOFs via enhanced permeability, selectivity and processability. For example, a MMM in which ZIF-90 was embedded in a 6FDA-DAM matrix shows a $\mathrm{CO}_{2}$ permeability of 720 Barrer at $25{ }^{\circ} \mathrm{C}$ and 2 bar, and a $\mathrm{CO}_{2} / \mathrm{CH}_{4}$ selectivity of 37 for an equimolar $\mathrm{CO}_{2} / \mathrm{CH}_{4}$ mixture, leading to a $54 \%$ enhancement in selectivity compared to the bare polymer. ${ }^{23}$ However, to date, very little work has been conducted to identify the active binding domains within such hybrid MMMs. This is not least because commonly employed diffraction techniques cannot be used since such composites tend to be amorphous. Thus, molecular details on the host-guest binding interaction within MMMs remain largely unknown, restricting the future design of improved MMMs.

Synchrotron micro-FTIR spectroscopy is a relatively new technique showing great value when probing gas uptakes in single crystalline MOFs. ${ }^{24,25}$ Synchrotron IR spectroscopy provides several benefits over in-house $I R$, the main one being its intensity, which provides about a 100 -fold increase in photon flux density over Globar sources. This increase gives a much improved signal-to-noise ratio leading to much higher quality spectra. Recently, this technique was used to probe the interactions of adsorbed $\mathrm{CO}_{2}$ in single crystals of $\left[\mathrm{Sc}_{2}\right.$ (BDC$\left.\left.\mathrm{NH}_{2}\right)_{3}\right] \quad\left(\mathrm{H}_{2} \mathrm{BDC}-\mathrm{NH}_{2}=\right.$ 2-amine-1,4-benzene dicarboxylic acid) which shows direct binding of oriented $\mathrm{CO}_{2}$ molecules to the 
free $\mathrm{NH}_{2}$ groups. ${ }^{24}$ More recently, this technique was also used to monitor the competitive gas adsorption between $\mathrm{CO}_{2}$ and $\mathrm{SO}_{2}$ in MFM-300(In)..$^{25}$

Herein, we report the fabrication of a new stable $M M M$ based on MFM-300(Al) ${ }^{26}$ and 6FDA-Durene-DABA (8.5/1.5) [6FDA $=4,4^{\prime}$-(hexafluoroisopropylidene) diphthalic anhydride, DABA $=3,5$-diaminobenzoic acid] (Figure 1 ) and its gas permeation properties. More importantly, we also report, to the best of our knowledge, the first example of the use of synchrotron micro-FTIR to probe the active binding domains within the $\mathrm{MMM}$ as a function of $\mathrm{CO}_{2}$ loading. This technique allows us to probe whether the increase in performance is through direct influence of the MOF filler or through the formation of a non-selective void network, which is a longstanding debate in the field.

MFM-300(Al) was selected for this study owing to its high stability and excellent $\mathrm{CO}_{2}$ adsorption capacity and selectivity towards $\mathrm{CH}_{4}$ and $\mathrm{N}_{2} .{ }^{26} \mathrm{MFM}-300$ (Al) has a 3D open structure with square-shaped 1D channels (pore size 5-6 ̊) comprising of Al-hydroxyl chains linked by biphenyl tetracarboxylate linkers. A 25 wt\% MFM-300(Al) loaded MMM was fabricated with 6FDA-Durene-DABA (8.5/1.5) using the solution casting method in a PTFE dish. To aid the interaction between the MOF particles and the polymer matrix, $25 \mu \mathrm{L}$ of a surface modifier [dimethoxymethylsilylpropyl-modified-poly(ethylene imine)] was added to coat the MOF particles without affecting their gas adsorption performance. The addition of the surface modifier produced a stable free-standing film, which could be readily delaminated from the substrate.

The morphology of the MMM and the distribution of the filler particles were assessed using scanning electron microscopy (SEM) (Figure 2). Energy dispersive X-ray (EDX) spectroscopy was also used to assess the distribution of MOF in the membrane (Figure S3). The SEM/EDX images confirm the homogenous distribution of MOF particles throughout the MMM without any apparent macro-voids, suggesting a strong affinity between the MOF particles and the polymer matrix (cross-section images are shown in Figure S2). Rod-like crystals
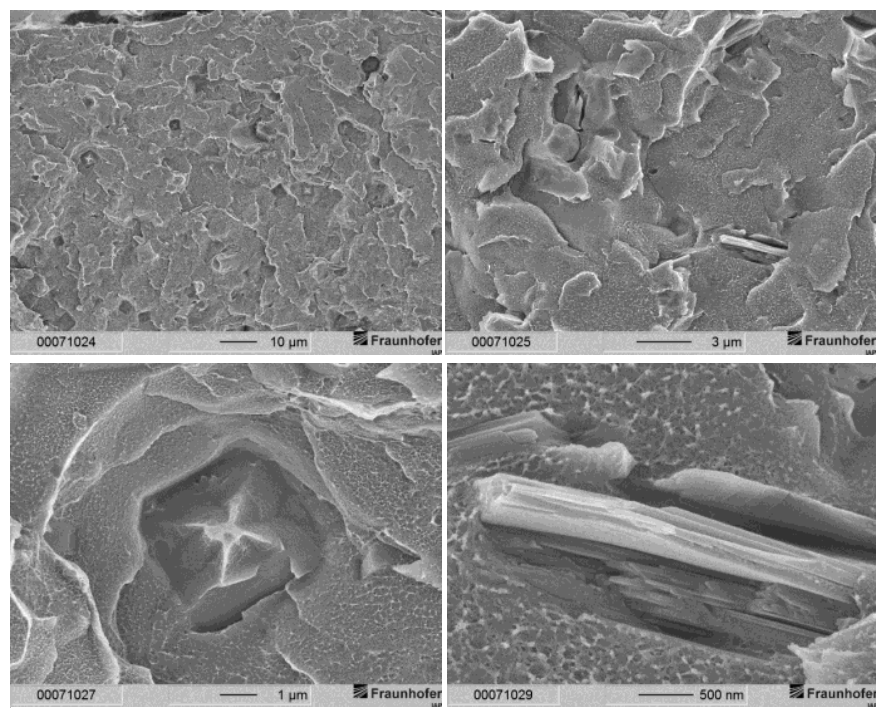

Figure 2 .SEM images of the MFM-300(AI)/6FDA-Durene-DABA mixed matrix membrane (MMM) showing the homogenous distribution of MOF particles within the membrane and the absence of macro-voids between the MOF particles and polymer matrix.

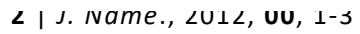

of MFM-300(Al) (ca. $2 \times 5 \mu \mathrm{m}$ ) are well embedded within the polymer matrix with the crystals remaining intact through the casting process. The large size of MOF particles is usually detrimental to membrane fabrication with nanoparticles being favored. ${ }^{27-29}$ However, SEM analysis suggests an absence of voids in this case. PXRD data confirm the retention of the MOF crystallinity when embedded within the MMM (Figure S1).

Single gas permeation tests were performed on both bare polymer and $\mathrm{MMM}$ to assess their permeation performance using the time lag method (Table S1). Addition of MFM-300(Al) into the polymer shows much improved $\mathrm{CO}_{2}$ permeability over the bare polymer (from 602 to 911 Barrer) at 303K. The increase in $\mathrm{CO}_{2}$ permeability, coupled with a decrease in the permeability of $\mathrm{CH}_{4}$ from 34 Barrer in the bare polymer membrane to 27 Barrer in the MMM, leads to a considerable increase of $94 \%$ in the $\mathrm{CO}_{2} / \mathrm{CH}_{4}$ ideal selectivity, from 17 for the bare polymer to 32 for the MMM.

Significantly, the simultaneous increase in $\mathrm{CO}_{2}$ permeability and ideal selectivity for $\mathrm{CO}_{2}$ vs $\mathrm{CH}_{4}$ moves this $\mathrm{MMM}$ well above the 2008 Robeson upper bound (Figure 3). Moreover, this MMM performs competitively to other reported 6FDAbased MMMs as well as the best-behaving MMMs using other polymer supports (Table S2). For example, a 16 wt\% ACOF1/Matrimid membrane showed a $\mathrm{CO}_{2} / \mathrm{CH}_{4}$ selectivity of $32.4 .{ }^{30}$ However, due to the inherently less porous nature of the Matrimid 5218 polyimide, the reported $\mathrm{CO}_{2}$ permeability is limited as 15.3 Barrer, much lower than that (911 Barrer) obtained from the MMM reported here.

In order to understand this increase in $\mathrm{CO}_{2}$ permeability and the binding interaction of $\mathrm{CO}_{2}$ within the $\mathrm{MMM}$, in situ synchrotron micro-FTIR was used to study the membrane. Sites were selected on the membranes under the optical microscope which gave a good signal-to-noise ratio as synchrotron microlR is highly sensitive to changes in sample thickness. Spectra of desolvated membrane samples were taken at $303 \mathrm{~K}$ in order to simulate the conditions used for the permeation measurements.

A separate portion of bare polymer membrane was used to examine the interaction between the polymer and $\mathrm{CO}_{2}$ in absence of MOF particles. Switching the gas flow from 10, 20, 40,60 to $80 \% \mathrm{CO}_{2}$ in $\mathrm{N}_{2}$ and then to $100 \% \mathrm{CO}_{2}$ allowed spectra to be taken in the presence of gas phase $\mathrm{CO}_{2}$, and enabled any changes resulting from the presence of $\mathrm{CO}_{2}$ to be followed as a function of $\mathrm{CO}_{2}$ partial pressure. A background spectrum was taken at each individual loading of $\mathrm{CO}_{2}$. The spectra were of

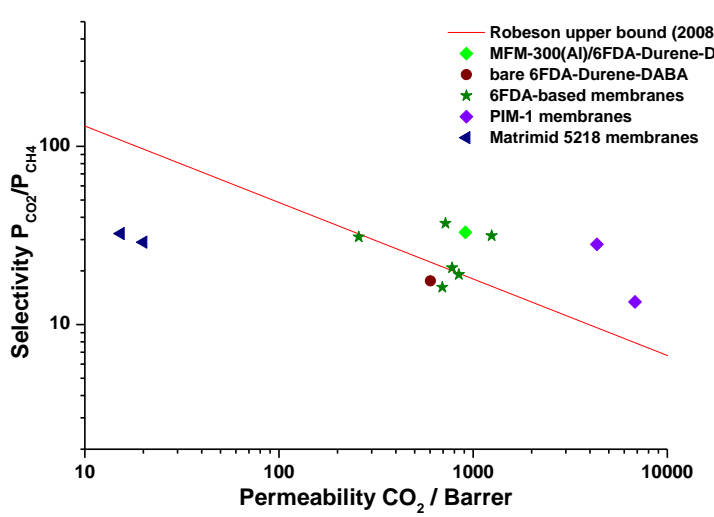

Figure 3. Comparison of the $\mathrm{CO}_{2}$ permeability and $\mathrm{CO}_{2} / \mathrm{CH}_{4}$ selectivity of MFM300(Al)/6FDA-Durene-DABA, the bare 6FDA-Durene-DABA polymer and a number of state-of-the-art membranes on the Robeson plot (numerical values are listed in Table S2). 
high quality and the $v(\mathrm{OH})$ stretching mode of MFM-300(Al) was observed at $3693 \mathrm{~cm}^{-1}$, enabling the direct observation of the interaction of $\mathrm{CO}_{2}$ with this group. The overtone peak associated with the $\mathrm{v}(\mathrm{CO})$ stretching mode of the imide $\mathrm{C}=\mathrm{O}$ from the polymer is observed at $3499 \mathrm{~cm}^{-1}$, allowing a direct comparison of the competitive interactions between the MOF and polymer with $\mathrm{CO}_{2}$.

Firstly, the bare polymer was studied in the presence of $\mathrm{CO}_{2}$. At 0 bar of $\mathrm{CO}_{2}$ the $\mathrm{v}(\mathrm{CO})$ overtone of the imide $\mathrm{C}=\mathrm{O}$ group was observed at $c a$. $3499 \mathrm{~cm}^{-1}$. Upon dosing with $\mathrm{CO}_{2}$ starting at $10 \%$ and increasing in increments to $100 \% \mathrm{CO}_{2}$, the combination and overtone bands of $\mathrm{CO}_{2}\left(v_{1}+v_{3}\right.$ and $\left.2 v_{2}+v_{3}\right)$ can be seen to grow in the spectra (Figure 4a). Although $\mathrm{CO}_{2}$ is adsorbed by the bare polymer, there is no notable polymer$\mathrm{CO}_{2}$ binding interaction, confirmed by the absence of any shift in the vibrational peaks associated with the polymer in the presence of $\mathrm{CO}_{2}$. The integrated peak areas (Figure 4b) for the bare polymer confirms the absence of any change in the $\mathrm{C}=\mathrm{O}$ vibrational mode whilst there is a steady increase, as expected, for the $\mathrm{CO}_{2}$ bands.

Investigations were then carried out to probe the behaviour of the MMM on loading of $\mathrm{CO}_{2}$ (Figure 4c). The MMM shows the same IR band associated with the $\mathrm{v}(\mathrm{CO})$ overtone of the imide carbonyl of the polymer at $3499 \mathrm{~cm}^{-1}$. The vibrational mode $\mathrm{v}(\mathrm{OH})$ of the MOF is also clearly observed at $3693 \mathrm{~cm}^{-1}$. The stepwise loading of $\mathrm{CO}_{2}$ is accompanied by the steady growth of the $\mathrm{CO}_{2}$ combination band at $3591 \mathrm{~cm}^{-1}$. The second combination band occurs beneath the hydroxyl vibration of the MOF; deconvolution of this peak shows that this band grows concurrently with $\mathrm{CO}_{2}$ loading, as expected. Due to the close proximity of the peaks associated with the $-\mathrm{OH}$ group it is difficult to determine the overall peak positions precisely. However, by repeating the experiment using ${ }^{13} \mathrm{CO}_{2}$ it was possible to conclude that a red shift occurs with a decrease in intensity of the peak due to $\mathrm{v}(\mathrm{OH})$ at $3693 \mathrm{~cm}^{-1}$ and growth of a new peak, at $3684 \mathrm{~cm}^{-1}$, which indicates the partial depletion of free $-\mathrm{OH}$ groups on $\mathrm{CO}_{2}$ loading, consistent with the formation of an $\mathrm{OH} \cdots \mathrm{OCO}$ binding interactions (Figure S4.3). This is a larger shift than that observed with ${ }^{12} \mathrm{CO}_{2}$ due to the increased mass of ${ }^{13} \mathrm{CO}_{2}$. The $\mathrm{CO}_{2}$ combination bands are also shifted due to the increased mass of ${ }^{13} \mathrm{CO}_{2}$ to $3500 \mathrm{~cm}^{-1}$ and $3616 \mathrm{~cm}^{-1}\left(v_{1}+v_{3}\right.$ and $2 v_{2}+v_{3}$, respectively). As seen for the bare polymer, the peak at $3499 \mathrm{~cm}^{-1}$ exhibits no shifts on $\mathrm{CO}_{2}$ loading, nor is a shift observed for the band at $3557 \mathrm{~cm}^{-1}$ (assigned to the $\mathrm{N}-\mathrm{H}$ imine stretching mode from the surface modifier) as validated by analysis of the peak areas for these bands (Figure $4 \mathrm{~d}$ ). This result indicates that the $\mathrm{MMM}-\mathrm{CO}_{2}$ binding is highly regio-selective, with $\mathrm{CO}_{2}$ showing a preferential interaction with the MOF crystals over the polymer. Interestingly, this is further supported by results obtained from the gas permeation measurements which show an increase in the solubility coefficient of $\mathrm{CO}_{2}$ from $26.09 \mathrm{~cm}^{3}$ (STP) $\mathrm{cm}^{2}$ atm $^{-1}$ in the bare polymer to $31.48 \mathrm{~cm}^{3}$ (STP) $\mathrm{cm}^{2}$ $\mathrm{atm}^{-1}$ in the MMM.
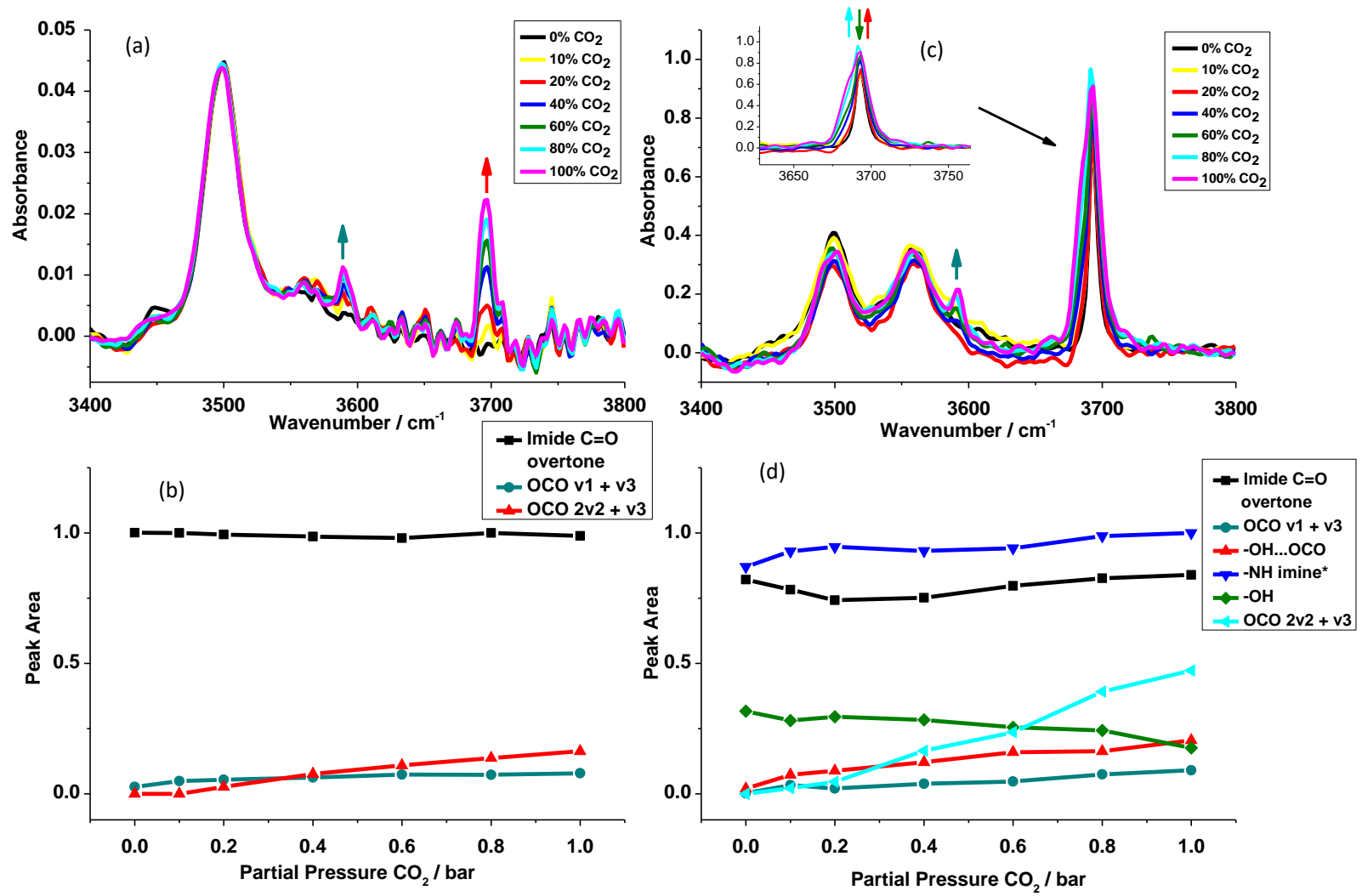

Figure 2. a) Micro-IR spectra of the bare polymer in the asymmetric $\mathrm{v}(\mathrm{CO})$ stretching region for $\mathrm{CO}_{2}$. b) Fitted peak areas showing adsorption of $\mathrm{CO}_{2}$ in $6 \mathrm{FDA}-\mathrm{Durene-DABA}$ as a function of partial pressure (areas normalised to the highest peak). c) IR spectra of MFM-300(Al)/6FDA-Durene-DABA in the $v(\mathrm{OH}$ ) stretching region of MFM-300(Al). The peak at $3557 \mathrm{~cm}^{-1}$ has been assigned to the $\mathrm{N}-\mathrm{H}$ imine stretching mode from the surface modifier. d) Fitted peak areas showing adsorption of $\mathrm{CO}_{2}$ as a function of partial pressure in $\mathrm{MFM}$ $300(A \mathrm{I}) / 6 F D A-D u r e n e-D A B A$ (areas normalised to the highest peak). 
By utilising in situ micro-IR spectroscopy, it is possible to obtain direct insight into the interactions of $\mathrm{CO}_{2}$ within a hybrid MMM, which is important in the design and coupling of new MOFs and polymers for gas separation applications. We found that although $\mathrm{CO}_{2}$ is adsorbed into the bare polymer there is no notable host-guest binding interaction. On inclusion of MFM-300(Al) into the polymer, there is a highly selective interaction between the $\mathrm{CO}_{2}$ and MOF particles as indicated by the observed shift of the $\mathrm{v}(\mathrm{OH})$ band in the MOF. This confirms that the MOF particles have a direct effect on the permeation of $\mathrm{CO}_{2}$ within this membrane rather than creating continuous voids through the membrane, as has been previously reported with zeolite-based MMMs. ${ }^{31}$ Thus, the MFM-300(Al) particles create homogenous selective pathways within the MMM to accelerate the permeation of $\mathrm{CO}_{2}$, but also to partially block the permeation of $\mathrm{CH}_{4}$ due to its poor binding interaction and adsorption. This is the basis for the observed overall enhancement of $\mathrm{CO}_{2}$ vs. $\mathrm{CH}_{4}$ selectivity in this MMM.

In conclusion, we have successfully fabricated a highly permeable and selective MMM incorporating a robust MOF MFM-300(Al). This MMM shows excellent $\mathrm{CO}_{2} / \mathrm{CH}_{4}$ separation performance and shows an increase of $94 \%$ in the ideal selectivity over the bare polymer. Characterisation of the MMM shows retention of crystallinity of the MOF within the polymer matrix. In situ synchrotron micro-IR spectroscopic experiments have confirmed that the MOF particles in this MMM are directly responsible for the increased $\mathrm{CO}_{2}$ permeability rather than through the formation of a void-rich network formed within the polymer matrix. The results reported herein confirm the value of synchrotron micro-FTIR spectroscopy when coupled to in situ gas loading as a means of providing previously unknown insights into the binding of gases within the MMM.

\section{Conflicts of interest}

There are no conflicts to declare.

\section{Acknowledgements}

We thank the EPSRC (EP/I011870) and the ERC for support. We thank Diamond Light Source for access to beamline B22.

\section{Notes and references}

1 B. Shi, R. Al-Dadah, S. Mahmoud, A. Elsayed, E. Elsayed, Appl. Therm. Eng., 2016, 106, 325-333

2 M. Savage, I. Da Silva, M. Johnson, J. H. Carter, R. Newby, M. Suyetin, E. Besley, P. Manuel, S. Rudić, A. N. Fitch, C. Murray, W. I. F. David, S. Yang, M. Schröder, J. Am. Chem. Soc., 2016, 138, 9119-9127.

3 J. Jiao, L. Dou, H. Liu, F. Chen, D. Bai, Y. Feng, S. Xiong, D.-L. Chen, Y. He, Dalton. Trans., 2016, 45, 13373-13382.

4 L. Zhang, C. Zou, M. Zhao, K. Jiang, R. Lin, Y. He, C.-D. Wu, Y Cui, B. Chen, G. Qian, Cryst. Growth Des., 2016, 16, 71947197.

5 Y.-P. Zhao, Y. Li, C.-Y. Cui, Y. Xiao, R. Li, S.-H. Wang, F.-K. Zheng, G.-C. Guo, Inorg. Chem., 2016, 55, 7335-7340.
6 T. N. Lieu, H. T. T. Nguyen, N. D. M. Tran, T. Truong, N. T. S. Phan, Ind. Eng. Chem. Res., 2016, 55, 11829-11838.

7 J. M. Taylor, S. Dekura, R. Ikeda, H. Kitagawa, Chem. Mater., 2015, 27, 2286-2289.

8 S. Pili, S. P. Argent, C. G. Morris, P. Rought, V. Garcia-Sakai, I. P. Silverwood, T. L. Easun, M. Li, M. R. Warren, C. A. Murray, C. C. Tang, S. Yang, M. Schröder, J. Am. Chem. Soc., 2016, 138, 6352-6355.

9 X. Zhao, Y. Li, Z. Chang, L. Chen, X. H. Bu, Dalton Trans., 2016, 45, 14888-14892.

10 S. Qiu, M. Xue, G. Zhu, Chem. Soc. Rev., 2014, 43, 61166140.

11 Y. Liu, Z. Ng, E. A. Khan, H.-K. Jeong, C.-b. Ching and Z. Lai, Microporous Mesoporous Mater., 2009, 118, 296-301.

12 Y. Liu, E. Hu, E. A. Khan and Z. Lai, J. Membr. Sci., 2010, 353, 36-40.

13 N. Stock, S. Biswas, Chem. Rev., 2012, 112, 933-969.

14 B. Seoane, J. Coronas, I. Gascon, M. E. Benavides, O. Karvan, J. Caro, F. Kapteijn, J. Gascon, Chem. Soc. Rev., 2015, 44, 2421-2454.

15 M. S. Jr. Denny, J. C. Moreton, L. Benz, S. M. Cohen, Nat. Rev. Mater., 2016, 1, 16078.

16 H. B. Tanh Jeazet, S. Sorribas, J. M. Román-Marín, B. Zornoza, C. Téllez, J. Coronas, C. Janiak, Eur. J. Inorg. Chem., 2016, 27, 4363-4367.

17 Y. Ban, Z. Li, Y. Li, Y. Peng, H. Jin, W. Jiao, A. Guo, P. Wang, Q. Yang, C. Zhong, W. Yang, Angew. Chem. Int. Ed., 2015, 54, 15483-15487.

18 J. Shen, G. Liu, K. Huang, Q. Li, K. Guan, Y. Li, W. Jin, J. Memb. Sci., 2016, 513, 155-165.

19 M. S. Denny, S. M. Cohen, Angew. Chem. Int. Ed., 2015, 54, 9029-9032.

20 T. Rodenas, M. van Dalen, E. Garcia-Perez, P. Serra-Crespo, B. Zornoza, F. Kapteijn, J. Gascon, Adv. Funct. Mat., 2014, 24, 249-256.

21 A. Sabetghadam, B. Seoane, D. Keskin, N. Duim, T. Rodenas, S. Shahid, S. Sorribas, C. Le Guillouzer, G. Clet, C. Tellez, M. Daturi, J. Coronas, F. Kapteijn, J. Gascon, Adv. Funct. Mat., 2016, 26, 3154-3163.

22 Q. Xin, J. Ouyang, T. Liu, Z. Li, Z. Li, Y. Liu, S. Wang, H. Wu, Z. Jiang, X. Cao, ACS Appl. Mater. Interfaces, 2015, 7, 10651077.

23 T. H. Bae, J. S. Lee, W. Qiu, W. J. Koros, C. W. Jones, S. Nair, Angew. Chem. Int. Ed., 2010, 49, 9863-9866.

24 A. Greenaway, B. Gonzalez-Santiago, P. M. Donaldson, M. D. Frogley, G. Cinque, J. Sotelo, S. Moggach, E. Shiko, S. Brandani, R. F. Howe, P. A. Wright, Angew. Chem. Int. Ed., 2014, 53, 13483-13487.

25 M. Savage, Y. Cheng, T. L. Easun, J. E. Eyley, S. P. Argent, M. R. Warren, W. Lewis, C. Murray, C. C. Tang, M. D. Frogley, G. Cinque, J. Sun, S. Rudić, R. T. Murden, M. J. Benham, A. N. Fitch, A. J. Blake, A. J. Ramirez-Cuesta, S. Yang, M. Schröder, Adv. Mater., 2016, 28, 8705-8711.

26 S. Yang, J. Sun, A. J. Ramirez-Cuesta, S. K. Callear, W. I. F. David, D. P. Anderson, R. Newby, A. J. Blake, J. E. Parker, C. C. Tang, M. Schröder, Nat. Chem., 2012, 4, 887-894.

27 Y. Cheng, X. Wang, C. Jia, Y. Wang, L. Zhai, Q. Wang, D. Zhao, J. Membr. Sci., 2017, 539, 213-223.

28 Z. Kang, Y. Peng, Z. Hu, Y. Qian, C. Chi, L. Y. Yeo, L. Tee, D. Zhao, J. Mater. Chem. A., 2015, 3, 20801-20810.

29 T. Rodenas, I. Luz, G. Prieto, B. Seoane, H. Miro, A. Corma, F. Kapteijn, F. X. Llabrés i Xamena, J. Gascon, Nat. Mater., 2014, 14, 48-55.

30 M. Shan, B. Seoane, E. Rozhko, A. Dikhtiarenko, G. Clet, F. Kapteijn, J. Gascon, Chem. Eur. J., 2016, 22, 14467-14470.

31 M. G. Suer, N. Baç and L. Yilmaz, J. Membr. Sci., 1994, 91, 7786. 